\title{
OBRAS MUNICIPALES: PROCEDIMIENTO APROBATORIO Y FINANCIACION
}

\author{
$351.712: 352$
}

\author{
por \\ Vicente Matas Morro \\ Secretario del Ayuntamiento de Lluchmayor (Baleares)
}

SUMARIO: I. ANTECEDENTES. - II. CONCEPTO. - III. CLASIFICACION: 1. POR LA FINALIDAD QUE PERSIGUEN: A) De urbanización. B) Ordinarias: a) De nueva planta: a') Patrimoniales. b') De uso o servicio público. b) De ampliación, mejora o conservación. 2. SEGúN LA LEGISLACIÓN QUE LAS REgUla: A) Obras sometidas a la Ley del Suelo. B) Obras sometidas a la Ley de Régimen local.-IV. FORMAS DE ACTUACION: 1. EN CASO de ObRAS SOMETIDAS a LA LEY del SUelo: A) En suelo urbano: a) Obras no previstas en el P. G. M. O. b) Obras previstas en el P. G. M. O. c) Obras en Municipios sin planificación. B) En suelo urbanizable programado. C) En suelo urbanizable no programado. D) En suelo no urbanizable. 2. EN CASO DE OBRAS SOMetidas a la Ley de RéGimen local: A) Previstas en algún elemento de planificación. B) No previstas en algún elemento de planificación. V. PROCEDIMIENTO PARA SU APROBACION: 1. OBRAS DE URBANIZACIÓN. 2. ObRas ORdiNARIAS: A) Sujetas a ia Ley del Suelo. B) Sujetas a la Ley de Régimen local.-VI. EJECUCION: 1. OBRAS DE URBANIZACIÓN. SISTEMAS DE EJECUCIÓN: A) Sistema de compensación: a) Sujeto. b) Ambito o extensión. B) Sistema de cooperación: a) Sujeto. b) Ambito o extensión. C) Sistema de expropiación. 2. OBRAS ORDINARIAS: A) Incluidas en algún elemento de planificación. B) No incluidas en elementos de planificación. 3. REFERENCIA ESPECIAL A LA CONCESIÓN ADMINISTRATIVA.-VII. FINANCIACION: 1. OBRAS DE URBANIZACIÓN: A) Sistema de compensación. B) Sistema de cooperación. C) Sistema de expropiación: a) En actuaciones por polígonos o unidades completas. b) En realizaciones concretas. D) Especial referencia a las cuotas o cánones de urbanización: a) Naturaleza. b) 
Procedimiento para su aprobación. c) Recursos contra el mismo. 2. OBRAS ORDINARIAS: A) Incluidas en algún elemento de planificación. B) No incluidas en elementos de planificación. - VIII CONCLUSIONES.

\section{ANTECEDENTES}

Hasta tiempos recientes, el Derecho administrativo español regulaba de una forma concreta y detallada las obras públicas, tanto estatales como locales. A tal fin existían la Ley General de Obras públicas de 13 de abril de 1977 y el Reglamento de 6 de julio del mismo año, por una parte, y de la otra, el Estatuto municipal de 8 de marzo de 1924 (arts. 158 y 180 y ss.), así como el Reglamento de Obras, Servicios y Bienes municipales de 14 de julio de aquel mismo año.

En igual sentido, los tratadistas (1), al estudiar la actividad material de las Entidades públicas, dedicaban algún capítulo a estudiar las obras públicas y sus efectos jurídicos, entre los cuales colocaban las normas que regulaban su contratación. Es decir, que consideraban a la obra el género, y su contratación, la especie.

Este enfoque ha variado sensiblemente en los últimos tiempos. La contratación ha pasado a ser el género y la obra la especie; para ello basta observar la Ley de Contratos del Estado de 8 de abril de 1965 (modificada el 17 de marzo de 1973) y su Reglamento de 28 de diciembre de 1967, la cual regula la práctica totalidad de los efectos de las obras públicas estatales (tales como proyectos, revisión, liquidación, etc.) aparte de la contratación, dándole a este concepto el significado estricto de selección de contratistas, que le dio el profesor Boquera Oliver en su estudio de esta denominación.

A esto podemos añadir, igualmente, que los estudiosos más modernos (2) abordan esta parcela de la actividad administrativa muy de pasada al diseccionar la contratación.

En el campo de la contratación local, si bien la Ley de Régimen local, texto refundido de 24 de junio de 1955, dedica una sección entera a regular las obras municipales, al parecer no se consideró

(1) Ver GASOON Y MARIN, J.: Tratado de Derecho administrativo, 13." ed., páginas 245 y ss., y Garcfa Oviedo, C.: Derecho administrativo, 5." ed., págs. 435 y ss.

(2) Ver Garcfa de EnTerRí, E., y Fernandez Rodriguez, Tomás Ramón: Curso de Derecho administrativo, 2.: ed., págs. 496 y 'ss. 
la materia lo suficientemente importante para destinarle un Reglamento, como se hizo con muchos otros aspectos municipales o como se realizó al publicarse el Estatuto municipal.

Sin embargo, sobre esta materia, y en el campo de la competencia municipal, ha venido a incidir, de una forma decisiva, la Ley sobre Régimen del Suelo y Ordenación urbana, pues no debemos olvidar que en esta Ley no se regula, únicamente, la planificación del suelo, sino también la ejecución de los Planes, mediante los correspondientes proyectos de urbanización, que se definen en el artículo 15 como "proyectos de obras», que "deberán detallar y programar las (obras) que comprendan con la precisión necesaria para que puedan ser ejecutadas por técnico distinto del autor del proyecto". Como ha dicho un insigne jurista español, lo más correcto sería decir que el proyecto ya no es planeamiento, sino un "plan concreto de realización de obras" (3).

Mención especial merecen los Planes especiales de reforma interior, que son auténticos proyectos de obras, como reconoce la misma Ley al tratar en el artículo 24 de «Planes y proyectos de saneamiento", al hablar de esta figura de planificación, suponemos que por considerar el legislador difícil o imposible concebir un Plan especial de saneamiento que no consista prácticamente en un proyecto de obra de tal naturaleza.

Además, el razonamiento anterior para los Planes y proyectos de saneamiento es igualmente válido para las demás finalidades de los Planes especiales de reforma interior, enumeradas en el artículo 23 , pues «operaciones encaminadas a la descongestión, creación de dotaciones urbanísticas y equipamientos comunitarios, saneamiento de barrios insalubres, resolución de problemas de circulación o de estética y mejora del medio ambiente de los servicios públicos u otros fines análogos", no pueden considerarse más que como proyectos de obras tendentes a dichas finalidades, los que en algún caso podrán afectar a la calificación del suelo, pero nada más.

En algunos momentos la Ley del Suelo parece que asimila dichos Planes especiales a parciales, por hacer el artículo 23, 2, una remisión al artículo 13 al regular el contenido formal de aquéllos; sin embargo, tal como hemos dicho antes, creo que en numerosos casos tendrán más de proyectos de urbanización que de Planes parciales, a

(3) González Pérez: Comentarios a la Ley del Suelo, 2.' ed. (1976), pág. 198. 
los que únicamente serán asimilables cuando modifiquen la calificación urbanística del suelo (4).

Es preciso, pues, una delimitación clara del concepto de Plan parcial, proyecto de urbanización y Plan especial que evite las confusiones entre los mismos y que permita una adecuada utilización de cada una de estas formas de planeamiento.

Esta regulación de las obras municipales en dos instrumentos jurídicos distintos, tales como la Ley de Régimen local y Ley del Suelo, con criterios distintos y aun opuestos en algunos casos, da ocasión a numerosos problemas en la aplicación de los mismos, en diversas fases de su tramitación y en particular en la parte de financiación de las mismas, como podremos apreciar a lo largo del presente estudio.

\section{CONCEPTO}

Según el artículo 128 de la Ley de Régimen local, «se considerarán como obras municipales todas las de nueva planta, reparación o entretenimiento que los Ayuntamientos ejecuten, tanto con sus propios fondos como con auxilio de otras Entidades públicas o de particulares, para la realización de servicios de la competencia municipal», concepto sensiblemente igual al que para las obras públicas aparece en el artículo 55 del Reglamento de Contratos del Estado.

En la Ley del Suelo no existe una definición expresa de las obras municipales o públicas.

(4) GonzÁlez Pérez: Comentarios..., págs. 205 y ss., que les da naturaleza de Planes de ordenación. En igual sentido se pronuncia en Los Planes de Urbanismo (1974), pág. 407 -sentencia del Tribunal Supremo de 7 de abril de 1967-. GonZÁLZBERENGUer, en cambio, los clasifica como Planes territoriales en su obra Teoria y práctica de la Ley del Suelo (1964), pág. 62. Morell, Luis, acepta la solución de GoNZález Pérez en «El proceso de departamentalización del urbanismo», en Documéntación Administrativa, núm. 170, págs. 93 y ss. 


\section{CLASIFICACION}

\section{POR LA FINALIDAD QUE PERSIGUEN}

\section{A) De urbanización}

Son aquellas que tienen por finalidad convertir a unos terrenos en urbanos o dotar de determinados servicios urbanos a terrenos que ya vienen teniendo la consideración de tales (5).

La Ley de Régimen local, en una confusa subclasificación de este tipo de obras, las dividía en obras de reforma interior, de ensanche, de extensión y de saneamiento, sin que a efectos prácticos tuviera la misma ninguna trascendencia.

Por una correcta determinación de cuáles obras deben considerarse como de urbanización y cuáles no, es preciso saber cuáles son los servicios indispensables para que un terreno tenga la consideración de urbano y cuáles son los que tienen por finalidad la mejora del hábitat.

El artículo 78 de la Ley del Suelo afirma rotundamente que «constituirán el suelo urbano:

a) Los terrenos a los que el Plan incluya en esa clase por contar con acceso rodado, abastecimiento de agua, evacuación de aguas y suministro de energía eléctrica, o por estar comprendidos en áreas consolidadas por la edificación al menos en dos terceras partes de su superficie, en la forma que aquél determine;

b) Los que en ejecución del Plan lleguen a disponer de los mismos elementos de urbanización a que se refiere el párrafo anterior».

Esto, por lo que hace referencia a los Municipios con planificación aprobada; pero para los Municipios sin Plan general, ¿qué se entenderá por suelo urbano? El artículo 81 lo especifica claramente al decir que en tal caso "constituirán el suelo urbano los terrenos que por contar con acceso rodado, abastecimiento de aguas, evacuación de aguas y suministro de energía eléctrica, o por estar

(5) Carceller Fernández, A., hace sinónimos los conceptos de obras de urbanización y obras costeadas por los propietarios beneficiados en su estudio "La ejecución de los Planes de ordenación en el texto refundido de la Ley del Suelo (REvista DE ESTUdios DE LA VIDA LOCAL, núm. 193, pág. 51). En igual sentido se pronuncia GoNZÁLEZ PÉREZ, en Comentarios a la Ley del Suelo, págs. 672-673. 
comprendido en áreas consolidadas por la edificación al menos en la mitad de su superficie, se incluyan en un proyecto de delimitación».

Está claro que la Ley declara como suelo urbano a aquellos terrenos dotados de determinados servicios o bien a los que se hallan comprendidos dentro de una línea en la que un porcentaje determinado se halle consolidado por la edificación; de aquí que al definir las obras de urbanización hallamos incluido en ellas no sólo a las que tienen por finalidad convertir a unos terrenos en urbanos, sino también a las que tienen por finalidad dotar a te. rrenos considerados ya como urbanos, en virtud de la delimitación correspondiente, y a pesar de ello no estar dotados de los servicios esenciales para tener tal calificación, bien de todos o algunos de éstos.

Ahora bien, ¿cuáles son los servicios que transforman a un terreno en urbano? Parece claro que son los previstos en los artículos 78 y 81 de la Ley del Suelo; sin embargo, debemos tener en cuenta que el artículo 122 incluye en los costes de urbanización, que deben ser sufragados por los propietarios afectados, "las obras de vialidad, saneamiento, suministro de agua y energía eléctrica, alumbrado público, arbolado y jardinería", con lo que se repiten los mismos servicios de los dos artículos citados en primer lugar, con algunas variaciones semánticas (se sustituyen las expresiones de acceso rodado, abastecimiento de agua y evacuación de aguas por vialidad, suministro de agua y saneamiento, completamente sinónimas), e incluyendo dos nuevos servicios: alumbrado público y el arbolado y jardinería.

Del contexto de todos los artículos estudiados nos inclinamos a deducir que, si bien estos dos últimos servicios no son necesarios para la calificación de un terreno como urbano, ni como solar, las obras de implantación de dichos servicios son obras de urbanización y, por tanto, incluidas dentro de esta calificación y sujetas a las normas que regulan este tipo de obras (6).

(6) No coincide con esta definición LÓPEZ Pellicer, J. A., en su libro Los proyectos de obras municipales, ver págs. 59 y ss. Sin embargo, con esta definición desaparece la duda que se le presenta sobre cómo slasificar determinadas obras como abastecimiento de agua, alcantarillado, etc., según consta en la nota 79 , pág. 64. 


\section{B) Ordinarias}

Para la definición de este tipo de obras nos sirve perfectamente la que figura en el artículo 130, 2, de la Ley de Régimen local, que dice: «Todas las demás obras no incluidas en el apartado anterior, y cuya realización es de la competencia municipal, serán obras municipales ordinarias»; es decir, que serán aquellas que, sin ser de urbanización según el concepto indicado en el apartado 3.1.1, tienden a cumplir cualquiera de los fines que para la actividad municipal señale el artículo 101 de la Ley de Régimen local.

Las hemos tenido que definir con un sentido negativo diciendo que son todas aquellas que no son de urbanización. Sin embargo, debemos hacer unas distinciones entre ellas, con lo que las podríamos subclasificar de la siguiente forma:

\section{a) De nueva planta}

Aquellas que consisten en la transformación del suelo de su forma natural y primigenia en otro artificial, modificado y, en definitiva, humano.

Estas obras a su vez se pueden dividir en dos grupos:

\section{a') Patrimoniales}

Serían aquellas que se realizan de forma normal indistintamente por los entes públicos o por las personas privadas, así, por ejemplo, la construcción de un garaje, de un almacén, la edificación de viviendas para funcionarios, etc., en los lugares autorizados por las normas de construcción en vigor.

\section{b') De uso o servicio público}

Serían aquellas cuyo uso es incompatible con el uso privado del suelo y cuya ubicación puede influir en forma determinante sobre el desarrollo de una población o de una zona de la misma, tal como un complejo deportivo, un mercado, un matadero, etc. 
VICENTE MATAS MORRO

b) De ampliación, mejora o conservación

Son aquellas que se realizan sobre otras ya realizadas, a las que conservan o modifican en algún aspecto (7).

\section{SEgún LA LEgislación QUe LAS REgUla}

\section{A) Obras sometidas a la Ley del Suelo}

Son aquellas que en la totalidad de su tramitación y ejecución se ajustan a la Ley del Suelo, siéndoles, por tanto, inaplicables las normas de la Ley de Régimen local. Sólo reúnen esta condición las obras que hemos calificado anteriormente como obras de urbanización, pues a éstas en ningún caso les es aplicable el régimen general de la Ley de Régimen local (8).

Sin embargo, hay otro tipo de obras que se hallan sometidas integramente a las disposiciones de la Ley del Suelo, salvo que, en algunos casos, y en lo que se refiere a su financiación, les es de aplicación lo dispuesto en la Ley de Régimen local, como veremos posteriormente en el apartado VII, 2, A). Estas obras son las que hemos calificado anteriormente como ordinarias de nueva planta destinadas a uso o servicio público, las cuales, para su ejecución, requerirán en todos los casos la tramitación de uno de los elementos planificadores previstos en la Ley del Suelo, como explicaremos en el apartado siguiente.

De todo lo anteriormente indicado se deduce que las obras que

(7) Esta clasificación no se opone en absoluto a la teoría de las obras de urbanización parcial elaborada por el Tribunal Supremo en diversas sentencias (sentencias de 22 de diciembre de 1961, 26 de mayo de 1967, 10 de octubre de 1973, etc.), pues para evitar la existencia de éstas se requiere en unos casos que sean de sustitución de elementos urbanístico, en otros de inexistencia de Plan de Ordenación urbana, pero en ningún caso que sean de urbanización parcial, por ser unas determinadas clases de obras.

(8) En sentido opuesto opina LOPEZ PELlicer en su estudio «El derecho de edificar en suelo urbano de Municipios que carecen de planeamiento urbanísticon, publicado en CUNAL, núm. 389, donde dice textualmente que uen los Municipios sin planeamiento urbanístico ni normas subsidiarias, la elaboración, aprobación y ejecución de proyectos de obras de urbanización, según lo dicho, no estarán sujetas, en principio, al régimen de la Ley del Suelo, sino al régimen común de la Ley de Régimen local y disposiciones que la complementan y desarrollan". En igual sentido se pronunciaba en su obra Los proyectos de obras municipales, págs. 65 y ss. 
consideramos sometidas a la Ley del Suelo son las de urbanización y las ordinarias de nueva planta destinadas a uso o servicio público, por la trascendencia que las mismas tienen o pueden tener sobre el futuro desarrollo de la población en la que se realicen.

\section{B) Obras sometidas a la Ley de Régimen local}

En este apartado se incluyen todas las de nueva planta, reparación o entretenimiento que ejecuten los Ayuntamientos para la realización de servicios cuya competencia les corresponda, según lo dispuesto en el artículo 101 de la indicada Ley de Régimen local, excepto las reseñadas en el párrafo anterior, que hemos dicho están sujetas a la Ley del Suelo, siempre que se trate de obras de nueva planta, pues la reparación o entretenimiento no pueden ser objeto de un Plan o proyecto y, por tanto, incapaces de pasar a ser reguladas por la Ley del Suelo.

Esta distinción plantea el problema de las obras, indicadas en el apartado III, 2, A), que se realicen en Municipios que carecen de planeamiento urbanístico aprobado. LOPEZ PELLICER sostiene que, al no poder aprobar proyectos de urbanización por no tener Plan parcial a ejecutar, según viene exigiendo el Tribunal Supremo, «la elaboración, aprobación y ejecución de los proyectos de obras de urbanización (a las que nosotros añadimos las ordinarias de nueva planta destinadas a uso y servicio público) no estarán sujetas en principio al régimen de la Ley del Suelo, sino al régimen común de la Ley de Régimen local» (9).

Entiendo que la solución antes apuntada es errónea, en base a los siguientes razonamientos:

1. En los Municipios carentes de Plan general o Normas complementarias y subsidiarias de planeamiento, la realización de obras, de las previstas en el apartado III, 2, A), deberá ir precedida de un Plan especial-proyecto de obras, pues si bien el artículo 17 de la Ley del Suelo determina que los Planes especiales se redactarán «en desarrollo de las previsiones contenidas en los Planes generales municipales, en los Planes directores territoriales de coordinación o en las Normas complementarias y subsidiarias de pla-

(9) Los proyectos de obras municipales, pág. 66. 
neamiento", no es menos cierto que en el apartado 3 del mismo artículo dice que contendrán las determinaciones necesarias para el desarrollo de aquellos instrumentos de planeamiento, "y, en su defecto, las propias de su naturaleza y finalidad debidamente justificadas y desarrolladas» (10). A mayor abundamiento, el artículo 23, 3, explica que "cuando se trate de operaciones de reformá interior no previstas en el Plan general», lo cual indica claramente que para la existencia de Planes especiales no se precisa ningún instrumento de planeamiento previo, sino que puede consistir en el primer y único escalón de la planificación de un Municipio, pues, como expresamente indica el artículo 17,1 , en ningún caso pueden sustituir a los Planes generales municipales (o Normas subsidiarias) como instrumentos de ordenación integral del territorio.

Con el desarrollo y regulación de los Planes especiales de reforma interior y de saneamiento se ha roto la dialéctica Plan generalparcial-proyecto de urbanización, y se ha permitido a los Municipios una actuación idéntica para situaciones iguales, con la dosis importante de clarificación jurídica que ello representa.

2. Según la disposición transitoria segunda de la Ley del Suelo de 12 de mayo de 1956, «las Comisiones Provinciales de Servicios Técnicos tendrán las atribuciones que les confiere la Ley de Régimen local con las salvedades siguientes:

(10) Al estudiar González Pérez (Comentarios..., págs. 204 y ss.) los Planes especiales y al llegar a la expresión "en su defecto", duda sobre la posibilidad de Planes especiales sin la existencia previa de Planes generales, directores territoriales de coordinación o normas subsidiarias o complementarias, y termina afirmando que, "dados los términos del apartado 1, parece que no". Como se ve, Ja frase no resulta muy convincente.

MORELl OCAÑA, Luis, llega a una conclusión más tajante: "Los Planes especiales tienen por finalidad el desarrollo de los Planes territoriales", a cuya conclusión llega por la distinta redacción que se da en las Leyes de 1956 y de 1975 al principio de los artículos reguladores de los Planes especiales, pero sin tener en cuenta para nada la expresión "en su defecto" del párrafo 3 del artículo 17, ni la regulación en tal caso de su contenido.

Por otra parte, si sólo pudieran existir Planes especiales que desarrollaran Planes o normas territoriales, qué diferencia jurídica existíría con los Planes parciales o los proyectos de urbanización, según los casos.

A mi modo de ver, la principal virtud práctica de los Planes especiales es la posibilidad de actuación municipal en casos necesarios y no previstos en los Planes territoriales, siempre que se trate de actuaciones particulares, no de la totalidad del territorio, upues en ningún caso pueden sustituir a los Planes generales municipales como instrumentos de ordenación integral del territorion, como dice el mismo artículo 17, párrafo 1, lo cual indica claramente que el legislador veía a los Planes especiales como al margen de los Planes territoriales, pues hasta previó la posibilidad de que éstos fueran sustituidos por aquéllos. 
a) Las facultades que señala el artículo 273 y los apartados a) y b) del artículo 275 de la citada Ley corresponderán a la Comisión Provincial de Urbanismo.

b) Las restantes facultades de la Comisión Provincial de Servicios Técnicos relacionadas con el urbanismo, las ejercerá conforme a los Planes aprobados o a las normas que dictaren los organismos competentes".

El artículo 273 de la Ley de Régimen local (que es el único que en estos momentos interesa) dice constituyen funciones resolutorias de la Comisión Provincial de Servicios Técnicos:

a) La aprobación de los Planes de urbanización.

b) La aprobación de ordenanzas de construcciones de viviendas.

c) La aprobación de proyectos de ensanche, reforma interior y saneamiento o urbanización parcial.

Parece clara, de lo expuesto anteriormente, la necesidad de tramitar todas las obras de carácter urbanístico y de primera planta de uso o servicio público, con una influencia decisiva en el desarrollo de la población, ajustadas a las disposiciones de la Ley del Suelo y a través de la Comisión Provincial de Urbanismo para su aprobación definitiva, sin que en ningún caso se exima de este procedimiento a los Municipios que carezcan de instrumentos planificadores.

\section{FORMAS DE ACTUACION}

\section{En caso de obras sometidas a la Ley del Suelo}

\section{A) En suelo urbano}

En este tipo de tèrreno se podrá actuar a través de dos formas de las previstas en la Ley del Suelo, bien mediante proyectos de urbanización o bien mediante Planes especiales de reforma interior, saneamiento o cualquier otra finalidad análoga, sin necesidad en ningún caso de aprobar previamente un Plan parcial de la zona afectada por las obras.

Esta conclusión se deduce de la simple lectura de los artículos 15,$1 ; 17,1$ y 2 , y 23 . En el artículo 15,1 , se dice claramente que 
los proyectos de urbanización son proyectos de obras que tienen por finalidad llevar a la práctica los Planes generales municipales en el suelo urbano. En el artículo 17 se define lo que son los Planes especiales al decir que se redactarán en desarrollo de las previsiones contenidas en los Planes generales municipales para determinados fines, o para la ejecución directa de obras correspondientes a la infraestructura del territorio o a los elementos de desarrollo urbano previstos en el número 2 , párrafo $d$ ), del artículo $8 .^{\circ}$, y en el número 1, párrafo $b$ ), del artículo 12, pero también podrán confeccionarse Planes especiales de reforma interior para las obras no previstas en el Plan general (art. 23, 3).

Los Planes especiales de reforma interior tienen por objeto la realización en suelo urbano de determinadas operaciones tendentes a la mejora del hábitat, tal como especifica el artículo 23,1 , y los de saneamiento de operaciones, que si bien no se especifican como de suelo urbano, corresponden a servicios netamente urbanos.

Tanto en los proyectos de urbanización como en los Planes especiales no se precisa de Plan parcial. pues para el primero de los casos el artículo 15, 1, prevé proyectos de urbanización que desarrollan Planes parciales independientes de los vistos anteriormente, y la teoría de los Planes especiales es independiente por completo de los Planes parciales.

Como vimos, los instrumentos de actuación son dos: el proyecto de urbanización y el Plan especial, pero ¿cuál de los dos deberá utilizarse en cada caso concreto?

a) Obras no previstas en el P. G. M.O.

En el caso de obras no previstas en el Plan general deberá acudirse necesariamente al Plan especial, el cual en ningún caso «modificará la estructura fundamental de aquél, a cuyo efecto se acompañará además un estudio que justifique su necesidad o conveniencia, su coherencia con el Plan general y la incidencia sobre el mismo» (art. 23, 3). 
b) Obras previstas en el P. G. M. O.

Cuando se trata de obras previstas en el Plan general, la utilización de un instrumento u otro dependerá de que para su ejecución se precisen determinaciones sobre la ordenación del suelo, el régimen del suelo o de la edificación no contenidas en el Plan general. Cuando sean necesarias dichas determinaciones se precisará un Plan especial y, en caso contrario, un Proyecto de urbanización, pues, como especifica el artículo 15, 1, éstos «no podrán contener determinaciones sobre ordenación ni régimen del suelo y de la edificación». Esta misma solución es aplicable a los Municipios que posean Normas subsidiarias de planeamiento aprobadas.

\section{c) Obras en Municipios sin planificación}

Como hemos dicho anteriormente, la solución será siempre la redacción de un Plan especial.

\section{B) En suelo urbanizable programado}

Si bien el artículo 81, 1, establece en forma muy expresa que "en los Municipios que carecieran de Plan general municipal de ordenación el territorio se clasificará en suelo urbano y suelo no urbanizable», la afirmación no debe tomarse en un sentido tan estricto como le da el indicado artículo, pues en el artículo 71, 4, se había dicho ya que "para la urbanización y edificación al amparo de Normas complementarias y subsidiarias...", lo cual indica que se puede urbanizar, claramente, al amparo de dichas Normas, y la posibilidad de existencia de terreno urbanizable en estos casos, que no es el contemplado por el artículo 81 . Por si pudiera dar lugar a dudas la expresión anterior, el mismo artículo 71, 4, especifica que para el desarrollo de las determinaciones urbanísticas de dichas Normas se confeccionarán los acorrespondientes Planes parciales».

Para la realización de obras municipales en este tipo de terrenos es preciso la aprobación previa de un Plan parcial que desarro- 
lle el Plan general o las Normas, al cual, como es obvio, seguirá el Proyecto o los Proyectos de urbanización correspondientes (11).

La regla anterior quiebra cuando se trata de realizar obras de infraestructura básica "relativas a las comunicaciones terrestres, marítimas y aéreas, al abastecimiento de agua, saneamiento, suministro de energía y otras análogas» (art. 8., 2 , s.), o de «estructura general y orgánica del territorio integrada por los elementos determinantes del desarrollo urbano, y, en particular, los sistemas generales de comunicación y sus zonas de protección, los espacios libres destinados a parques públicos y zonas verdes en proporción no inferior a cinco metros cuadrados por habitante y el equipamiento comunitario y para centros públicos» (art. 12, 1, b), que serán objeto de un Plan especial de los previstos en el artículo 17, 2, sin necesidad de Plan parcial alguno, tal como determina el artículo 84,1 , al decir que en el suelo urbanizable programado no se podrán realizar obras o instalaciones, "salvo las que hayan de ejecutar mediante la redacción de los Planes especiales a que se refiere el artículo diez y siete punto dos» (12).

\section{C) En suelo urbanizable no programado}

En este tipo de terrenos, como paso previo a cualquier actividad planificadora o realizadora, se deberá aprobar un Programa de actuación urbanística, y posteriormente desarrollarlo a través de los Planes parciales y Proyectos de urbanización que sean precisos.

Ahora bien, ¿es aplicable al mismo la solución del artículo 84, 1, para las obras de infraestructura previstas en el mismo? Si bien ningún artículo de la Ley del Suelo aboga en forma expresa por este sistema, creemos que la respuesta afirmativa se deduce de la propia realidad, pues en el caso de que una obra de tal clase debiera pasar por terreno urbanizable no programado, éste no podría gozar de mayor protección jurídica que uno que se halla programado. Y esta solución afirmativa creemos que es igualmente aplicable a los terrenos no urbanizables, pues, de lo contrario, en éstos no existiría posibilidad alguna de actuación urbanística más que

(11) En este mismo sentido, ver González PÉrez, Comentarios..., pág. 469.

(12) Ver Carceller Fernández, “La ejecución de los Planes...», págs. 47 y 48. 
aquella tendente a concederle una especial protección, según dispone el artículo 86, 2 (13).

\section{D) En suelo no urbanizable}

Creo que ha quedado suficientemente clara cuál es nuestra postura en esta clase de terrenos en el apartado anterior (14).

2. EN CASO dE ObRAS SOMETIDAS A LA LEY DE RÉGIMEN LOCAL

\section{A) Previstas en algún elemento de planificación}

Si se trata de obras ordinarias, cuya ejecución se previó en un Plan general, Plan parcial o en un Plan especial, deberá redactarse el correspondiente Proyecto de urbanización. Igual solución cabe para las obras realizadas al amparo de Normas subsidiarias.

\section{B) No previstas en algún elemento de planificación}

En estos casos deberá formularse un Proyecto de obra municipal de los previstos en el artículo 131 de la Ley de Régimen local.

Ahora bien, ¿qué diferencia existe entre un Proyecto de urbanización y un Proyecto de obra municipal? De la simple comparación de los artículos que regulan ambas figuras jurídicas se puede deducir la diferencia entre ambos. En los dos se exigen unos planos y una memoria descriptiva de las obras a realizar, y, por otra parte, el artículo 131 de la Ley de Régimen local habla de unas condiciones y especifica cuáles son éstas al exigir mediciones, cuadros de precios, presupuesto y pliego de condiciones.

Como se ve, las exigencias en ambos instrumentos legales son

(13) A todo ello hay que añadir lo dispuesto en el artículo 123, que prevé la obligación de «subvenir a la ejecución o suplemento de las obras exteriores de infraestructura" en suelo no urbanizable por parte de los propietarios afectados, lo cual indica claramente la posibilidad de actuación en los terrenos con tal calificación.

(14) La posibilidad de actuación no lleva, sin embargo, en este tipo de terrenos, la correlativa obligación de subvenir a los costes de urbanización, por faltar el presupuesto de la plusvalía afectada que concurre en los demás casos. 
sensiblemente iguales, sin embargo la Ley de Régimen local exige un requisito más: una relación detallada y valoración aproximada de terrenos $y$ construcciones que hayan de ocuparse $y$, en su caso, expropiarse.

Esta diferencia es debida a que los Proyectos de urbanización «no podrán contener determinaciones sobre ordenación ni régimen del suelo", que es un contenido propio de los Planes, que son los únicos que llevan implícita la declaración de utilidad pública de las obras y la necesidad de ocupación de los terrenos y edificios a efectos de expropiación (art. 64, 1, de la Ley del Suelo), lo cual lleva aparejado necesariamente una modificación de su régimen.

Los proyectos de obras municipales, al no apoyarse jurídicamente en ningún Plan de ordenación previo, deben tener necesariamente entre su documentación el elemento que les permita ocupar o expropiar los terrenos necesarios para la ejecución de las obras proyectadas.

\section{PROCEDIMIENTO PARA SU APROBACION}

\section{ObRas DE URBANIZACIÓN}

Como hemos visto anteriormente, para la realización de obras de este tipo se precisa actuar, en todos los casos, mediante alguno de los instrumentos previstos en la Ley del Suelo, bien sea mediante Proyectos de urbanización, bien mediante Planes especiales; por tanto, en todos los casos, para su aprobación, deberá seguirse el procedimiento previsto en los artículos 41 y 43 de la Ley del Suelo, que no vamos a diseccionar en este estudio, pues creemos que muy poco podríamos aportar a lo dicho ya por insignes tratadistas, $y$, por tanto, remitimos al lector a cualquiera de ellos para un conocimiento detallado del mismo (15).

Esto no obstante, deseamos hacer un alto en dos cuestiones que consideramos de gran interés práctico: el procedimiento abreviado para Planes especiales, previsto en el artículo 43, 3, y la competencia para su aprobación, según lo dispuesto en el artículo 35 .

(15) Ad exemplum, ver González Pérez: Comentarios... y Los Planes de urbanismo; GonzálezrBerenguer, Teoría y práctica de la Ley del Suelo; Comentarios a la Ley del Suelo, de ABella, etc. 
El artículo 43, 3, prevé un procedimiento abreviado para la tramitación de ciertos Planes especiales, consistente en una aprobación previa (término que se considera sinónimo de inicial) (16) por parte del Ministerio de la Vivienda o de la Comisión Provincial de Urbanismo, según se trate de Planes que afecten a capitales de Provincia o poblaciones de más de cincuenta mil habitantes o, por el contrario, a Municipios que no reúnan ninguna de las dos características anteriores: una información pública, en todo caso, en la capital de la Provincia y una aprobación definitiva por los citados órganos.

$¿$ Qué Planes especiales podrán tramitarse con este procedimiento abreviado? La Ley es taxativa, debe tratarse necesariamente "de Planes especiales definidos en el Capítulo I de este Título (el primero), cuya finalidad fuere mejorar las condiciones urbanísticas y especialmente las estéticas de los pueblos de una Comarca o ruta turística y que no compredieren en el planeamiento modificación de alineaciones ni supusieren la destrucción de edificios»; es decir, que exige la existencia concurrente de cuatro condiciones: una objetiva, otra finalista, una tercera referente a la actividad predominante y finalmente una de inmutabilidad. Veamos:

a) Objetiva. Sólo afecta a los Planes especiales previstos y regulados en el Título I, Capítulo I, que es tanto como decir a todos los Planes especiales, pues en ningún otro lugar de la Ley del Suelo se regula ningún tipo distinto de tales Planes. Quedan, sin embargo, fuera de este procedimiento toda clase de Planes generales, parciales y Normas complementarias y subsidiarias.

b) Finalista. Deben tender, inexcusablemente, a mejorar las condiciones urbanísticas y estéticas de una zona. Pero nosotros nos preguntamos si es posible redactar un Plan especial que no tenga por finalidad el mejorar las condiciones urbanísticas del lugar afectado por el mismo. Hacerse la misma pregunta referida a las condiciones estéticas ya sería más aventurado, no obstante creo que en ningún caso podrá desecharse este procedimiento por no cumplir el Plan esta condición.

c) Actividad predominante. Esta condición exige que se trate de Planes que afecten a "pueblos de una Comarca o ruta turística», expresión que puede dar lugar a dificultades de interpretación, tan-

(16) Gonzalez Pérez, Comentarios..., pág. 320. 
to por la dificultad de determinar cuándo una Comarca o ruta puede considerarse turística como por el inconveniente derivado de la utilización del vocablo pueblo, que puede tomarse como sinónimo de Municipio y como entidad de población.

d) Inmutabilidad. Para acogerse al procedimiento aquí estudiado es preciso que los Planes especiales no modifiquen para nada el régimen urbanístico de ningún terreno, ni aun en aspectos tan minúsculos como una modificación de alineaciones.

De todo lo dicho con anterioridad deducimos la escasa aplicabilidad de este procedimiento, ni la razón de su existencia.

La otra cuestión que creo vale la pena estudiar con cierto detenimiento es el de la competencia para la aprobación de Planes especiales.

El artículo 35, 1, después de fijar la competencia para la aprobación del Plan nacional y de los Planes directores territoriales, establece que el Ministerio de la Vivienda o las Comisiones Provinciales de Urbanismo, según que se trate de capitales de Provincia o poblaciones de más de 50.000 habitantes, o en el resto de los casos, podrán aprobar toda clase de Planes, entre los cuales hay que incluir los especiales, pues es regla jurídica aceptada por todos que donde la ley no distingue no debemos distinguir; sin embargo, en el apartado 2 el legislador se cree obligado a hacer una salvedad, y dice que "cuando la iniciativa de los Planes especiales se deba a Entidades locales o urbanísticas especiales, su aprobación corresponderá: a) si desarrollan un Plan general de ordenación, a los órganos competentes para aprobar los Planes parciales; $b$ ) en los demás casos, al Ministro de la Vivienda».

No entraremos en el apartado $a$ ) del párrafo anterior, por cuanto no introduce ninguna modificación en la regla general, pero veamos cuáles son las consecuencias del apartado b).

Supongamos que una Corporación local desee solucionar un problema de circulación o de algún servicio público con un Plan especial de reforma interior de los regulados en el artículo 23, 1, que a su vez desarrollá el artículo 17, 1, o supongamos que esta. misma Corporación desea construir una fuente, o un abrevadero, o dotar de agua a un edificio municipal, como, por ejemplo, el Matadero municipal, mediante Plan especial de los previstos en el artículo 24,2 y 3 , que igualmente desarrolla el artículo 17, 1, obras 
que no se hallan previstas en el Plan general o del cual se carece; pues bien, nuestra pregunta es: ¿en estos casos su aprobación corresponderá al Ministro de la Vivienda? De acuerdo con el artículo 35,2 , es indiscutible que sí, pero yo me pregunto, ¿no se habrán pasado los legisladores en su centralismo en casos como éstos?, ¿en qué situaciones pensarian al aprobar esta norma?, ¿es posible una interpretación más adecuada a las circunstancias reales? (17).

Nuestra opinión es que al redactar este precepto se tuvo en cuenta, solamente, los primeros casos de Planes especiales previstos en el artículo 17, 1, es decir, aquellos que tienden a la ordena. ción de recintos y conjuntos artísticos, protección del paisaje y de las vías de comunicación y conservación del medio rural en determinados lugares, en cuyos eventos será precisa, normalmente, la intervención de determinados organismos estatales, tales como el Ministerio de Educación y Ciencia, Obras Públicas o Agricultura. La finalidad de atribuir en estos casos la resolución final al Ministro de la Vivienda sería el evitar los posibles conflictos de atribuciones en órganos inferiores de la Administración y conseguir la coordinación precisa en estos casos (18).

No parece, en cambio, que se contemplaran en aquel momento los Planes especiales de reforma interior y saneamiento, en los cuales es más reducida la intervención de órganos estatales y donde es difícil justificar la injerencia del Ministro de la Vivienda, cuando en realidad se trata de obras que sólo interesan a la población del Municipio afectado, y en algunos casos sólo a una parte del mismo.

Por todo lo anteriormente expuesto considero que la competencia que el apartado a) del párrafo 2 del artículo 35 concede al Ministro de la Vivienda debe entenderse sólo en caso de existir sobre la materia que pretende regular el Plan especial correspondiente una competencia sustancial y decisiva de algún Departamento estatal.

(17) MoRell OcaÑa, quizá con visión más centralista, observa otro fallo de este artículo consistente en la falta de previsión de intervención del Ministerio de la Vivienda en el caso de Planes especiales redactados por un Ministerio distinto de aquél ( $₫$ El proceso de departamentalización del urbanismo», pág. 95).

(18) En sentido parecido Morell OCAÑA, «El proceso...», pág. 95. 


\section{OBRAS ORDINARIAS}

\section{A) Sujetas a la Ley del Suelo}

Al definir las obras sujetas a la Ley del Suelo hemos dicho que las hay de dos clases: $a$ ) obras de urbanización, y $b$ ) las calificadas como de nueva planta destinadas al uso o servicio público.

Dejando aparte las de urbanización, que ya estudiamos en la sección anterior, debemos indicar que el resto de las incluidas en el apartado deben tramitarse igualmente de acuerdo con lo dispuesto en la Sección cuarta, Capítulo II del Título I de la Ley del Suelo, por la sencilla razón de que no puede realizarse ninguna obra de «ensanche, reforma interior y saneamiento de urbanización parcial» (artículo 273 de la Ley de Régimen local) sin la aprobación del Proyecto de urbanización o Plan especial correspondiente, tanto si existe planificación general del Municipio como si ésta no existe, tal como indicamos anteriormente.

Esta interpretación proviene de la consideración de que la Ley del Suelo regula la planificación y la ejecución de las obras que puedan influir en el desarrollo de una población a través de los instrumentos de planificación, sin que puedan rellenarse con lo que se crea conveniente o necesario en cada momento, lo cual queda claro en el artículo $1 .^{\circ}$, al decir que «es objeto de la presente Ley la ordenación urbanística en todo el territorio nacional", especificando el artículo $2 .^{\circ}$ lo que entiende por actividad urbanística, y que no se concreta sólo en el planeamiento, aunque en muchos casos se ha cargado el acento sobre este aspecto, descuidando los restantes (19).

Si bien la disposición transitoria segunda de la Ley del Suelo de 1956 sólo transfiere la competencia de aprobación de la Comisión Provincial de Servicios Técnicos a la Comisión Provincial de Urbanismo, sin hablar para nada del procedimiento previo a seguir, según la interpretación nuestra no cabe otro procedimiento que el indicado anteriormente.

(19) Gonzalez Pérez, en Comentarios..., pág. 94, dice que ael llamado Derecho urbanístico (cuya pieza básica es la Ley del Suelo) no es una disciplina jurídica autónoma, sino un conjunto de normas jurídicas de naturaleza distinta informadas por principios harto diferentes. Lo único que existe común entre estas normas es el objeto social regulado por ellas». 


\section{B) Sujetas a la Ley de Régimen local}

La definición de estas obras es residual, pues se trata de aquellas que siendo de competencia municipal, según el artículo 101 de la Ley de Régimen local, no son obras de urbanización, ni tampoco de ensanche, reforma interior, saneamiento o urbanización parcial o, lo que es lo mismo, de nueva planta destinadas al uso o servicio público.

En estos casos, el procedimiento será el previsto en el artículo 132 de la Ley de Régimen local, consistente en aprobación provisional por el Ayuntamiento y. posteriormente aprobación definitiva por la Comisión Provincial de Servicios Técnicos, cuando se trate de Municipios de población inferior a 50.000 habitantes y que no sean capitales de Provincia. En el caso de tratarse de Municipios capital de Provincia o con población superior a 50.000 habitantes, no se precisa aprobación alguna de organismo distinto del Ayuntamiento, tal como sostiene LóPEz Pellicer en su obra Los proyectos de obras municipales, por cuanto la «competencia a la Comisión Central de Urbanismo hay que entenderla limitada, rationae materiae, al ámbito urbanístico. Además, según queda dicho, este órgano no existe en la actualidad, sin que quepa entender asumidas por el Ministerio de la Vivienda funciones resolutorias no comprendidas dentro del ámbito material de su competencia» (20).

\section{EJECUCION}

1. Obras de uRbanización. Sistemas de ejecución

La Ley del Suelo distingue tres sistemas de ejecución de las obras de urbanización previstas en los instrumentos correspondientes de planificación: el de compensación, el de cooperación y el de expropiación, con unas características y finalidades muy distintas para cada uno de ellos y que vamos a estudiar en detalle a continuación.

Uno de los problemas que no estaban claros con anterioridad a la publicación del texto refundido de la Ley del Suelo era el de

(20) Página 118 de la indicada obra. 
si los sistemas de actuación eran aplicables sólo a actuaciones generales que afectaran integramente a un polígono o también eran aplicables a los casos de actuaciones concretas y determinadas. El artículo 117, 1, ha venido a dar una contestación clara y concreta al decir textualmente que «la ejecución de los Planes y de los Programas de actuación urbanística se realizará por polígonos completos, salvo cuando se trate de ejecutar directamente los sistemas generales o alguno de sus elementos o de realizar actuaciones aisladas en suelo urbano", lo cual indica expresamente la posibilidad de ejecutar, por cualquiera de los sistemas indicados, las actuaciones aisladas o concretas.

\section{A) Sistema de compensación}

Este sistema es el más respetuoso con la libertad de actuación de los particulares afectados, reduciendo la Administración su actuación a un simple control de la actividad de los particulares, que se concreta principalmente en la inclusión de un representante de la Administración actuante en el órgano rector de la Junta de Compensación, institución máxima del sistema (21), cuyos Estatutos deberá aprobar igualmente la Administración (arts. 127, 4, y 126, 2, de la Ley del Suelo), y en la obligación de recibir el Municipio correspondiente, en pleno dominio y libre de cargas, todos los terrenos de cesión obligatoria y las obras o instalaciones que deban ejecutar a su costa los propietarios. Esta última obligación lleva como consecuencia necesaria la facultad de la Corporación municipal correspondiente de exigir que las obras e instalaciones a entregar se ajusten estrictamente a los Planes y Proyectos que sirvan de base a la actuación urbanística (22).

En todo lo demás, la iniciativa corresponde integramente a los particulares afectados por las obras de urbanización.

(21) GonzAlez PÉREZ las califica de entidades urbanísticas colaboradoras por antonomasia».

(22) GonZÁEZ Pérez opina que este precepto es inaplicable sin la existencia del correspondiente reglamento; en cambio, CARCELLER cree que la Junta de Compensación será «directamente responsable frente a la Administración competente de la urbanización completa». 


\section{a) Sujeto}

El sujeto activo de las obras en este sistema de actuación es el particular o los particulares propietarios de los terrenos ordenados, que pueden actuar bien con carácter particular y privado, caso de que todos los terrenos ordenados pertenezcan a un solo titular, bien a través de la Junta de Compensación, para cuya constitución será suficiente que estén de acuerdo propietarios que representen el 60 por 100 de la superficie total del polígono o unidad de actuación (art. 126).

También podrán formar parte de la citada Junta de Compensación las empresas urbanizadoras que vayan a participar con los propietarios en la gestión del polígono o unidad de actuación (artículo 127,2 ).

\section{b) Ambito o extensión}

Las obras a realizar serán las que se determinen en el Plan o Programa de actuación o en el acuerdo aprobatorio del sistema (artículo 126, 1), lo que indica claramente que no es preciso y consustancial al sistema la realización por parte de los propietarios afectados de todas las obras incluidas en el Plan o Programa.

Ahora bien, esta situación da lugar a una serie de interrogantes a cual más interesante. Veamos. ¿Cuáles obras deberán realizar necesariamente los propietarios y cuáles podrán ser dispensadas por la Administración? ¿Pueden oponerse los afectados a realizar las obras que no sean obligatorias o es una facultad discrecional de la Administración el concederlo? ¿Cómo deben financiarse las obras que no se realicen por los propietarios afectados y que redunden en beneficio de los mismos?

Intentemos contestar a estas preguntas. Las obras que necesariamente deberán realizar los propietarios serán las de urbanización, que, como hemos dicho anteriormente, coinciden con las indicadas en el artículo $122,1, a$ ), ya que ésta es una carga que va aneja inseparablemente a la propiedad de los terrenos, como a ella van añadidos los beneficios de la urbanización de los mismos.

En cuanto a la segunda pregunta, consideramos que la respuesta correcta es que los afectados tienen el derecho a negarse a rea- 
lizar a su costa las obras que no sean de urbanización, aun adoptando el sistema de compensación para la ejecución de la urbanización, pues en ningún lugar se exige la realización de otras obras que las previstas en el artículo 122, y como dice García DE ENTERRfa (23), basándose en el artículo 6. $.^{\circ}, 2$, del Reglamento de Servicios de las Corporaciones locales, uno de los principios generales del Derecho, especialmente aplicables al Administrativo, es el de in dubio pro libertate.

Esta interpretación no conduce necesariamente a que los afectados por la urbanización carezcan de toda obligación respecto a las obras no consideradas de urbanización, sino que tendrán el deber de financiarlas en parte, aunque esta financiación será diferente, según que el Municipio en el que se realice la urbanización posea presupuesto especial de urbanismo $o$ no, pues en el primer cáso serán de aplicación las contribuciones especiales previstas en el artículo 198 de la Ley del Suelo, de acuerdo con lo resuelto en las sentencias del Tribunal Supremo de 26 de mayo de 1967, 10 de octubre de 1973, etc. (24), que podrán llegar en todos los casos hasta el 90 por 100 del costo de las obras, y en el segundo caso será posible el Real Decreto 3.250/1976, en sus artículos 23 y siguientes, que regulan las contribuciones especiales, con los porcentajes que señala el artículo 29 del mismo, ya que de los prescritos en la norma 9. ${ }^{a}, 5 .{ }^{a}$, de la Ley 48/1966 sobre modificación parcial del Régimen local, son distintos ambos tipos de contribuciones especiales.

\section{B) Sistema de cooperación}

En este sistema, la Administración va adquiriendo ya un mayor protagonismo, pues los propietarios aportan el suelo de cesión obligatoria y ella ejecuta las obras de urbanización con cargo a aquéllos, lo cual lleva aparejado, en la mayoría de los casos, la repar-

(23) Curso de Derecho administrativo, Civitas, pág. 75.

(24) Estas sentencias y bastantes más sobre la materia deciden que las contribuciones especiales previstas del artículo 198 sólo pueden aplicarse en el caso de existencia de un Plan de ordenación definitivamente aprobado o de un proyecto de primera o nueva urbanización, bien sea total o parcial, en suelo urbano o urbanizable, pero en todo caso tramitado de acuerdo con lo dispuesto en la Ley del Suelo; en caso de no ser así, se calificarán como obras de urbanización parcial, y recobra «todo su imperio el sistema ordinario o normal de la Ley de Régimen local» (sentencia de 10 de octubre de 1973). Ver nota 34. 
celación de la zona, con el fin de distribuir equitativamente los beneficios y cargas de la urbanización. Existen dos casos regulados por la Ley en los que es innecesaria la reparcelación: a) cuando resulta «suficientemente equitativa la distribución de los beneficios y cargas» (art. 131, 2); b) «cuando, por las circunstancias de edificación en una actuación urbanística, no fuere posible llevar a cabo la reparcelación material de los terrenos de toda parte de la misma, superior a un 50 por 100 de la superficie afectada", en cuyo caso procederá la indemnización sustitutoria entre los afectados (artículo 125, 2). Si bien este caso parece referirse sólo al de la cesión del 10 por 100 a que se refiere el número 3 del artículo 84 , considero que esta carga de la cesión obligatoria es de la misma categoría jurídica que el resto de las mismas.

\section{a) Sujeto}

Como hemos dicho anteriormente, las obras en este caso son realizadas directamente por la Administración mediante cualquiera. de los sistemas regulados en la Ley de Régimen local, es decir, la subasta, el concurso, el concurso-subasta o la adjudicación directa, corriendo a cargo de los beneficiados el pago de las mismas a través de unas cuotas o participaciones proporcionales al valor de las fincas adjudicadas en la reparcelación o que posean los propietarios en el caso de que ésa fuera innecesaria. Estas cuotas o participaciones las veremos con detenimiento al estudiar la financiación de las obras.

\section{b) Ambito o extensión}

Creo que aquí puede repetirse íntegramente lo dicho en el apartado VI, $1, \mathrm{~A}, a)$ y $b$ ).

\section{C) Sistema de expropiación}

En este sistema la actividad privada desaparece en absoluto, ya que la expropiación "comprenderá todos los bienes y derechos» incluidos en el polígono o unidad de actuación a que se aplique el sistema (art. 134, 1). 
Como se ve en este caso, al particular no le queda ni siquiera el terreno edificable, que pasa a ser de propiedad pública, salvo en los casos en que, en lugar de aplicarse a un sistema general de ordenación urbanística del territorio, se aplique únicamente a la ejecución de alguno de sus elementos, o para realizar las actuaciones aisladas en suelo urbano, tal como prevé el apartado 2 del artículo 134, en cuyo caso, para la financiación de la expropiación, serán aplicables las contribuciones a que se refiere el artículo 145 (25).

\section{OBRAS ORDINARIAS}

\section{A) Incluidas en algún elemento de planificación}

Este tipo de obras serán realizadas normalmente por la Administración mediante cualquiera de las formas previstas en las normas de contratación, si bien en el caso de adoptarse el sistema de compensación, los particuares, bien directamente en el caso de los terrenos de un solo titular, bien a través de la Junta de Compensación, podrán asumir la realización de las mismas, a lo cual no podrá oponerse la Administración, salvo caso de interés público debidamente justificado.

\section{B) No incluidas en elementos de planificación}

En estos casos será aplicable íntegra y únicamente el Reglamento de Contratación de las Corporaciones locales (26).

\section{REFERENCIA ESPECIAL A LA CONCESIÓN ADMINISTRATIVA}

Todas las obras, tanto las de urbanización como las ordinarias, pueden ser objeto de concesión administrativa; si están afectas a un servicio público $\mathrm{y}$, por tanto, al amparo del artículo 114 del

(25) Carceller: "La ejecución de los Planes...», págs. 66 y ss. González Pérez hace hincapié en que la expropiación para realizar actuaciones aisladas debe ser necesariamente en suelo urbano, pág. 711 de Comentarios...

(26) Sentencias del Tribunal Supremo de 23 de junio de 1966, 26 de mayo de 1967 y 10 de octubre de 1973. 
Reglamento de Servicios, puede adjudicarse a un concesionario previa la tramitación del expediente correspondiente.

En el caso de que existiere ya un concesionario para determinado o determinados servicios, igualmente la Corporación podrá encargar la ejecución de las obras que afecten a los mismos a aquél, al amparo de lo dispuesto en el artículo 127, 1, 1. ${ }^{\mathrm{a}}, a$ ), del Reglamento de Servicios, siempre con la contrapartida de mantener el equilibrio de la concesión, tal como dispone el apartado 2 del mismo artículo.

\section{FINANCIACION}

\section{Obras de URBanización}

La financiación de estas obras está dominada por tres principios básicos: el de totalidad, el de posibilidad de pago en especie y el de expropiación como sanción.

El primero obliga a los particulares al pago íntegro de los costos de urbanización, tanto en la actuación por polígonos completos como por unidades concretas, y la Administración no puede eximirles de esta obligación más que en el caso de uresultar excesivas las cargas en relación con el escaso aprovechamiento previsto para las zonas edificables» (art. 121) y previo un procedimiento largo y dificultoso.

El segundo está regulado en el artículo 122, 2, al decir que el pago de los costes de urbanización "podrá realizarse, previo acuerdo con los propietarios interesados, cediendo éstos gratuitamente y libres de cargas terrenos edificables en la proporción que se estime suficiente para compensarlos».

El problema se presenta cuando el previo acuerdo no se produce, ¿entonces puede una de las dos partes obligar a la otra a aceptar esta situación? Nuestra opinión es que no, por cuanto el acuerdo de las partes se ha previsto por la Ley como una condición sine qua non para poder aceptar esta solución.

El principio de expropiación viene regulado en el artículo 124, 2, al determinar que uel incumplimiento de las obligaciones y cargas impuestas por la presente Ley habilitará a la Administración competente para expropiar los terrenos afectados $»$, si bien debe enten- 
derse como subsidiario y complementario de lo dispuesto en el artículo 100 y siguientes de la Ley de Procedimiento administrativo de 17 de julio de 1958, que tiene carácter preferente (27), pues de lo contrario se llegaría al absurdo de que la Administración (principalmente la municipal) no podría llevar a cabo sus planificaciones por falta de posibilidades económicas en el caso de que un propietario afectado, cuya propiedad tuviera un valor elevado, se negara a cumplir sus obligaciones y la Administración se viera obligada a expropiarle.

\section{A) Sistema de compensación}

Como hemos indicado anteriormente, en este caso las obras son realizadas directamente por la Junta de Compensación y financiadas por los miembros de la misma, siendo las cantidades adeudadas en tal concepto exigibles por la vía de apremio (art. 130, 2), para lo cual no se precisa de más trámite que la petición de la Junta a la Administración actuante.

¿Cómo se realizará la distribución de los costos entre los propietarios afectados y cuál será el módulo aplicable?

A nuestro entender, la base de reparto deberá ser el valor de las fincas adjudicadas en la reparcelación, y si ésta fuera innecesaria, el de las aportadas, y en función del cual se distribuirán los gastos ocasionados por la urbanización mediante la confección de un expediente, tramitado por la Junta, del cual se daría notificación personal a los afectados, y que sería aprobado igualmente por la Junta. Contra este acuerdo cabría recurso de alzada ante la Administración (art. 172, 5).

\section{B) Sistema de cooperación}

El expediente consistiría básicamente en la determinación de las cuotas o cánones a pagar por los afectados por la urbanización de los terrenos. La financiación de las obras corresponden íntegramente, como indicamos anteriormente, a los propietarios afec-

(27) En igual sentido se pronuncia GonzAlez Pérez: Comentarios..., pág. 678. 
tados por la urbanización, que la harán efectiva a través de las cuotas o cánones de urbanización (28), previa la entrega de los terrenos de cesión obligatoria.

\section{C) Sistema de expropiación}

En este sistema se deben distinguir dos formas de actuación: una, por polígonos o unidades de actuación completas, y otra, por realizaciones concretas, en cada una de las cuales la financiación de las obras públicas es distinta.

\section{a) En actuaciones por poligonos o unidades completas}

En este caso se procederá a la expropiación de los terrenos incluidos en el polígono, tanto los de cesión obligatoria como los edificables, una vez realizada la urbanización, los cuales pasarán, integramente, a formar parte del patrimonio municipal.

En aplicación del principio de posibilidad de pago en especie, la Administración podrá efectuar el pago del justiprecio mediante la entrega de parcelas urbanizadas, de acuerdo siempre con los expropiados (art. 142, 1).

Los costos de la urbanización correrán integramente de cargo de la Administración actuante, que se resarcirá de los mismos a través de las cesiones de los terrenos edificables resultantes, que no podrá ser por precio inferior al de costo, salvo que se destinen a atender necesidades de viviendas de carácter social (art. 166, 1).

\section{b) En realizaciones concretas}

Este sistema, según el artículo 134, 2, puede aplicarse igualmente "para la ejecución de los sistemas generales de la ordenación urbanística del territorio o la de alguno de sus elementos, o para

(28) LLISET las denomina acuotas de urbanización. (Revista de Derecho Urbanistico, enero-febrero 1976), mientras que GONZALEZ-BERENGUER habla del acanon de urbanización» (Teoria y práctica de la ley del Suelo, págs. 232 y ss.). Otros autores no les dan denominación especial y prefieren estudiarlas como cargas $\mathbf{u}$ obligaciones inherentes a la propiedad. 
realizar actuaciones aisladas en suelo urbano", en cuyo caso no es de aplicación lo previsto en los artículos siguientes, sino "se aplicará siempre el procedimiento de la Ley de Expropiación forzosa, sin perjuicio de que la tasación de los terrenos se realice con arreglo a los criterios de valoración de la presente Ley» (art. 144), pudiéndose aplicar contribuciones especiales sobre los propietarios especialmente beneficiados para la repercusión de aquellos costos de expropiación, pues no debemos olvidar que en este caso sólo se expropian los terrenos de cesión obligatoria, quedando los edificables en propiedad de los particulares (29).

Pero observemos que en este caso la Ley detiene su procedimiento en el momento en que se expropian los terrenos necesarios para la ejecución de las obras, pero no indica a quién corresponde la financiación de las mismas, ni a través de qué procedimiento o institución. ¿Cuál será, por tanto, la institución aplicable en este caso?

A nuestro modo de ver, la única que puede aplicarse es la del canon o cuota de urbanización exigible a los propietarios afectados por la obra, que serán los incluidos en la delimitación de la unidad de actuación, realizada de acuerdo con el artículo 117, 3, para la distribución justa de los beneficios y cargas derivados del planeamiento.

\section{D) Especial referencia a las cuotas o cánones de urbanización}

Como hemos visto, las obras de urbanización de unos terrenos se satisfacen en todos los casos, excepto en el sistema de expropiación en actuaciones por polígonos o unidades completas, mediante cuotas o cánones de urbanización; es, por tanto, una institución jurídica de suma importancia en el orden práctico, ya que de su efectividad depende en gran parte la operatividad en el campo del urbanismo (30). Veamos ahora cuáles son sus características:

(29) Para un estudio de los distintos tipos de expropiación previstos en la Ley del Suelo, ver Gonzalez PEREz: Comentarios..., págs. 710 y ss.

(30) LLISET, en su estudio aLas cuotas de urbanización», Revista de Derecho Urbanistico, enero-febrero 1976, básico para el conocimiento de la institución, dice que asi no se maneja con soltura este medio de financiación del urbanismo, resultará muy difícil, en la mayoría de los casos, la ejecución de los Planes urbanísticos». 


\section{a) Naturaleza}

El primer problema que se plantea es el de si se trata de una exacción o de otra clase de ingreso. Los artículos 120 y 132, 1, las califican de cargas de la urbanización, y como dice GonZález PÉREZ, lo hacen "en sentido rigurosamente técnico"; es indiscutible, por tanto, que no se trata de una exacción, sino de una carga de la propiedad. En igual sentido se pronuncia LLISET BORRELL en su artículo "Las cuotas de urbanización» (31).

Ahora bien, esta carga lleva impícita una obligación de cumplimiento por parte del sujeto pasivo de la misma, ¿o sólo es exigible cuando aquél de forma voluntaria desea utilizar su propiedad en un determinado sentido, en el de urbanizarla? La doctrina está unánimemente de acuerdo en señalar que esta carga lleva inherente la obligación de llevarla a cumplimiento cuando así se exija por la Administración, hallando su fundamento en el principio de aceptación de las plusvalías, que es tanto como decir de la recuperación por la sociedad de los beneficios que se derivan de la urbanización.

\section{b) Procedimiento para su aprobación}

Según LLISET, «en cualquier caso se seguirá el procedimiento reparcelatorio" (32), con cuya afirmación no estamos en absoluto de acuerdo, por cuanto el artículo 132, 1, distingue perfectamente entre la reparcelación y la determinación de las cuotas de urbanización, pues ésta se realizará en función del "valor de las fincas que les sean adjudicadas en la reparcelación", lo cual indica claramente que la reparcelación deberá ser previa a la determinación de las cuotas.

Es decir, que la Ley prevé claramente dos clases de aportaciones por parte de los propietarios afectados: una, de terrenos de cesión obligatoria que pueda dar lugar al procedimiento reparcelatorio de la zona afectada, y otra, de pago de las obras de urba-

(31) DE LOS MOzoS prefiere denominarlas obligaciones propter rem, por considerar impropia la denominación de carga (citado por CARCELLER en aLa ejecución de los Planes..., pág. 54).

(32) aLas cuotas...», pág. 62. 
nización mediante las correspondientes cuotas o cánones de urbanización. Ahora bien, ¿cuál será el procedimiento aplicable para la determinación de las citadas cuotas?

Consideramos que hasta que se regule debidamente en los reglamentos esperados de la Ley del Suelo, y teniendo en cuenta que el fundamento de las cuotas es el mismo que el de las contribuciones especiales, según reconocen LLISET y GARCía DE ENTERRfa (33), su aprobación debería ajustarse al procedimiento previsto para aquellas exacciones, con la variedad de que las asociaciones administrativas de propietarios se constituirán con carácter potestativo por parte de la Administración o de los interesados, según reconoce expresamente el artículo 131, 3.

\section{c) Recursos contra el mismo}

Al independizarse el procedimiento reparcelatorio del procedimiento para la determinación de las cuotas de urbanización, deja de jugar para éste el artículo 100, 2, con las consiguientes restricciones a la vía contencioso-administrativa, que señala LLISET en su $\tan$ repetido estudio.

Al tratarse, como hemos dicho anteriormente, de una obligación a la que se da ejecución mediante lo previsto en los artículos 100 y siguientes de la Ley de Procedimiento administrativo, lo que procede es el recurso de reposición como previo al contencioso-administrativo, según lo previsto en el artículo 52 de la Ley reguladora de la Jurisdicción contencioso-administrativa.

\section{OBRAS ORDINARIAS}

A este tipo de obras no les es de aplicación los principios que enumeramos al tratar de la financiación de las obras de urbanización, pues no se trata de obras que producen una modificación sustancial del terreno, sino obras que representan una mejora del hábitat $\mathrm{y}$ que, por tanto, no pueden aplicarse íntegramente a los terrenos mejorados, sino a las personas beneficiadas por las mismas.

(33) LLISET: «Las cuotas...», pág. 5D 


\section{A) Incluidas en algún elemento de planificación}

En este caso no son de aplicación las cuotas de urbanización, pues éstas tienen que ser necesariamente por la totalidad del costo de las obras (salvo los casos concretos), que la Ley sólo prevé para las obras de urbanización, por tanto hay que buscar otra figura jurídica aplicable en este caso.

A nuestro entender, la solución aplicable dependerá de que el Ayuntamiento correspondiente, para atender a las obligacions derivadas de la actividad urbanística, haya formado presupuesto especial de urbanismo o lo realice a través del presupuesto ordinario. En el primer caso podrá aplicar las contribuciones especiales previstas en el artículo 198 con el máximo «del 90 por 100 del coste total, con carácter uniforme», mientras que si sigue el segundo sistema deberá acudirse a las contribuciones especiales previstas en el Real Decreto 3.250/1976, de 30 de diciembre (34).

\section{B) No incluidas en elementos de planificación}

En este caso deberá acudirse inexcusablemente a lo dispuesto en el antes citado Real Decreto 3.250/1976 para las contribuciones especiales.

\section{CONCLUSIONES}

1. Las clasificaciones de las obras municipales, trascendentales a efectos jurídicos, son aquellas que las dividen en obras de urbanización y obras ordinarias, así como en obras sujetas a la Ley del Suelo y obras sujetas a la Ley de Régimen local, quedando,

(34) El Tribunal Supremo no exige el que se posea presupuesto especial de urbanismo para la aplicación de las contribuciones especiales en la Ley del Suelo; sin embargo, éstas son un ingreso propio del presupuesto especial de urbanismo y no del presupuesto ordinario. Por otra parte, parece que algunos casos de contribuciones especiales de los regulados en el Decreto $3.250 / 1976$, serían de imposible aplicación, al menos teóricamente hablando; nos referimos a apertura de calles, construcción de redes de alcantarillado, etc., típicas obras de urbanización y, por tanto, sujetas a la Ley del Suelo; sin embargo, de hecho deberán aplicarse en numerosos casos. 
por tanto, desvirtuada y sin efectividad la clasificación que figura en el artículo 129 de esta última Ley.

2. ${ }^{a} \quad$ Todas las obras de urbanización deben realizarse bajo la regulación de la Ley del Suelo, tanto en su aspecto formal como económico, lo cual representa tramitar el correspondiente elemento de planificación y aplicación de cuotas de urbanización por la totalidad del costo de las mismas, salvo los casos especiales regulados por la Ley.

3. ${ }^{a}$ Todas aquellas obras ordinarias que produzcan una determinada configuración del suelo, por el servicio público que ellas llevan anejo, deberán tramitarse por los procedimientos previstos en la Ley del Suelo, aunque su financiación podrá realizarse a través de ésta o de las normas propias del Régimen local.

4. ${ }^{a} \quad$ El resto de las obras ordinarias, que se limitarán casi exclusivamente a las de conservación y mejora de las existentes, se ajustarán en todo a la legislación de Régimen local. 


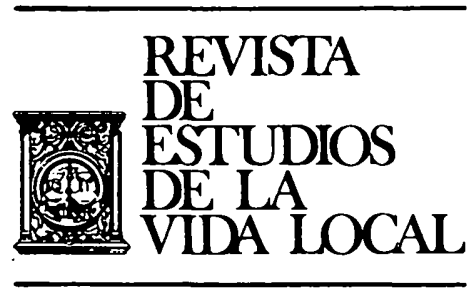

\section{CRONICAS}


REVL-1978, núm. 198. MATAS MORRO, VICENTE. OBRAS MUNICIPALES: PROCEDIMIENTO APRO... REVL-1978, núm. 198. MATAS MORRO, VICENTE. OBRAS MUNICIPALES: PROCEDIMIENTO APRO... 